\title{
CORRESPONDENCE
}

\section{The Treatment of Type 2 Diabetes}

by Prof. Dr. med. Andreas F. H. Pfeiffer, Prof. Dr. med. Harald H. Klein in issue $5 / 2014$ and the Drug Commission of the German Medical Association (Arzneimittelkommission der Ärzteschaft, $\operatorname{Akd} \ddot{\mathrm{A}})$.

The article can also be used for the purpose of collecting CME points. It is of note that the selected authors are exclusively hospital clinicians and that none of the authors from the DEGAM diabetes working group was involved. Dapagliflozin should not be used in patients older than 75. On the other hand, the number of diabetes patients older than 80 is steadily rising. I would have wished for a differentiated reflection on the use of metformin in this age group, and not for quotes from the widely known prescribing information. The authors are likely to be well aware of the fact that in other European countries, the threshold for the glomerular filtration rate is lower. As a GP who is active in continuing medical education I will not recommend this article.

DOI: 10.3238/arztebl.2014.0432b

\section{REFERENCES}

1. Pfeiffer AFH, Klein $\mathrm{HH}$ :The treatment of type 2 diabetes Dtsch Arztebl Int 2014; 111: 69-82. corresponds to my own experience, that diabetes patients who regularly consume alcohol develop polyneuropathies and diabetic foot more often than those who don't. A further argument is the not insubstantial amount of "empty" calories, which is likely to get in the way of the recommended weight loss. For this reason I do not think that your recommendation is expedient - or do you have study results that confirm the recommendation to be health promoting or at least not harmful?

DOI: 10.3238/arztebl.2014.0432a

\section{REFERENCES \\ 1. Pfeiffer $\mathrm{AFH}$, Klein $\mathrm{HH}$ :The treatment of type 2 diabetes. Dtsch Arztebl Int 2014; 111: 69-82.}

\section{Dr. med. Christian Roth}

Obermoschel

roth.ch@t-online.de

\section{Conflict of interest statemen}

The author declares that no conflict of interest exists.

\section{General Practitioners Were Neglected}

Without any further explanation, the three authors refer preferentially to the algorithm proposed by the German Diabetes Society (Deutsche Diabetes Gesellschaft, DDG). Patients with type 2 diabetes often present with complex symptoms, and most of them are treated by general practitioners. As an experienced GP I do not see any identifiable benefit in the equal status given in the article to the substance dapagliflozin; for this reason, this medication is not mentioned in the third therapeutic stage by the German College of General Practitioners and Family Physicians (Deutsche Gesellschaft für Allgemeinmedizin und Familienmedizin, DEGAM)
Dr. med. Manfred Lohnstein

Friedberg

Iohnstein.m@t-online.de

\section{Conflict of interest statement}

The author is a member of the German College of General Practitioners and Family Physicians (Deutsche Gesellschaft für Allgemeinmedizin und Familien-

Pfeiffer and Klein refer readers to the initial publications of the Look AHEAD Study $(1,2)$ and write: "In the Look AHEAD (Action for Health in Diabetes) trial, intensive lifestyle modification was tested against conventional diabetes support and education in a group of 5000 diabetic patients over a period of four years; intensive training brought about a mean weight loss of $4.5 \mathrm{~kg}$ compared with conventional training. The extent of weight loss was directly correlated with reductions in the $\mathrm{HbAlc}$ fraction (by $0.3-1 \%$ ), triglyceride concentrations, and systolic and diastolic blood pressure, as well as with a rise in the HDL cholesterol level."

Unfortunately Pfeiffer and Klein do not explain what they mean by "intensive lifestyle modification." From the original articles $(1,2)$, readers will find out that patients received weekly counseling in the first 6 months, and three times per month in the subsequent 6 months, in individual and group sessions, from dieticians, behavioral counselors, and exercise specialists. In the following 3 years patients were seen at least once a month and additionally contacted by telephone or email. It is obvious that such an intervention strategy is completely removed from any reality of treatment. medizin, DEGAM)

\section{Limited Prospects of Success}


The benefit described by Pfeiffer and Klein is pronounced only in the first year and then continuously tails off. At the end of the fourth year, the surrogates of the intervention group hardly differ from those in the control group.

The study was terminated prematurely after 9.6 years (3) because in spite of intensive lifestyle modification, the rate of clinically relevant end points (cardiovascular death, myocardial infarction, stroke, admission to hospital for angina pectoris) was not reduced.

This negative result does, of course, not mean that patients should not receive detailed advice. But the chances of success are limited. Doctors as well as patients should be aware of this in order to avoid being put under pressure.

D0I: 10.3238/arztebl.2014.0432c

\section{REFERENCES}

1. The Look AHEAD Research Group: Long-term effects of a lifestyle intervention on weight and cardiovascular risk factors in individuals with type 2 diabetes mellitus. Arch Intern med 2010; 170: 1566-75.

2. Wing RR, Lang W, Wadden TA, et al.: Benefits of modest weight loss in improving cardiovascular risk factors in overweigth and obese individuals with type 2 diabetes. Diabetes Care 2011; 34: $1481-6$

3. The Look AHEAD Research Group: Cardiovascular effects of intensive lifestyle intervention in type 2 diabetes. N Engl J Med 2013; 369: 145-54.

4. Peiffer AFH, Klein $\mathrm{HH}:$ The treatment of type 2 diabetes. Dtsch Arztebl Int 2014; 111: 69-82.

Prof. Dr. med. Frank P. Meyer

Wanzleben-Börde

U_F_Meyer@gmx.de

Conflict of interest statement

The author declares that no conflict of interest exists.

\section{Skepticism Is Unjustified}

The skepticism expressed in the article with regard to sulfonylureas is unjustified. In a recent Cochrane metaanalysis (1), second generation sulfonylureas had fewer cardiovascular side effects than metformin; mortality was the same. By comparison, the cited retrospective data provide low-level evidence. The article does not contain any concrete data on the adverse effects of sulfonylureas. Weight gain as a side effect of these drugs is clinically not relevant: $1.3 \mathrm{~kg}$ in 2 years (2) and $1.7 \mathrm{~kg}$ in 10 years (UKPDS). Hypoglycemia caused by sulfonylureas is rare: about $0.5 /$ patient/year, for example, for glimepiride+metformin (2). These cases of hypoglycemia are mostly mild and occur in the first three months after the start of the treatment, when $\mathrm{HbA1c}$ values in the sulfonylurea groups drop more notably than in the comparator groups.

The authors write that treatment with DPP-4 inhibitors does not carry a risk of hypoglycemia. In combination with insulin or insulinotropic substances, however, the risk of hypoglycemia is increased by DPP-4 inhibitors, and if required the treatment has to be adjusted.
The evidence for the explained lifestyle interventions is low. An example: the lifestyle intervention in the Look AHEAD Study did not prevent cardiovascular end points.

With regard to GLP-1 analogues, no benefit has been found with regard to clinical end points. There have so far not been sufficiently large studies that really prove or exclude the risk of pancreatic cancer in patients being treated with GLP-1 analogues. The increase in spontaneous reports of pancreatic cancer cases under GLP-1 treatment remain a cause for concern. The indication for this class of substances is altogether extremely rare.

The benefits of intensified insulin treatment in patients with type 2 diabetes that the authors propose are elusive. A randomized comparison of the different forms of insulin therapy did not show any significant differences; quality of life is rather reduced under intensive treatment (3). DOl: 10.3238/arztebl.2014.0433a

\section{REFERENCES}

1. Hemmingsen B, Lund SS, et al.: Targeting intensive glycaemic control versus targeting conventional glycaemic control for type 2 diabetes mellitus. Cochrane Database Syst Rev 2013; 11 CD008143.

2. Gallwitz B, Rosenstock J, Rauch T, et al.: 2-year efficacy and safety of linagliptin compared with glimepiride in patients with type 2 diabetes inadequately controlled on metformin: a randomised, double-blind, non-inferiority trial. Lancet 2012; 380 : 475-83.

3. Holman RR, Farmer AJ, Davies MJ, et al.: 4-T Study Group. Three-year efficacy of complex insulin regimens in type 2 diabetes. N Engl J Med 2009; 361: 1736-47.

4. Pfeiffer AFH, Klein $\mathrm{HH}$ : The treatment of type 2 diabetes. Dtsch Arztebl Int 2014; 111: 69-82.

emer. Prof. Dr. med. Heinz-Harald Abholz

Institut für Allgemeinmedizin, Universität Düsseldorf

abholz@med.uni-duesseldorf.de

Dr. med. Günther Egidi

Hausarztpraxis, Bremen

for the German College of General Practitioners and Family Physicians

(Deutsche Gesellschaft für Allgemeinmedizin, DEGAM)

\section{Prof. Dr. med. Ulrich Alfons Müller}

Universitätsklinikum Jena, Funktionsbereich Endokrinologie und

Stoffwechselerkrankungen der Klinik für Innere Medizin III

\section{Prof. Dr. med. Joachim Spranger}

Charité Universitätsmedizin Berlin, Klinik für Endokrinologie,

Diabetes und Ernährungsmedizin

for the Drug Commission of the German Medical Association (Arzneimittel-

kommission der Deutschen Ärzteschaft, AkdÄ)

\section{Conflict of interest statement}

Prof Abholz is a member of DEGAM and was involved in developing the disease management guideline for type 2 diabetes.

Dr Egidi has received a honorarium for participating in the expert workshop of the Profil Institute, on patient relevant end points in diabetology.

Prof Müller has received honoraria for acting as an expert adviser from IQWiG and for CME events from the German Medical Association.

Prof Spranger has received consultancy fees from Bristol Myers Squibbs and Amgen. For preparing scientific CME events he has received honoraria from AstraZeneca, Bayer, BMS, MSD, Berlin-Chemie, Sanofi, and Novo. He has also received funding from Sanofi for a research project that he himself initiated.

\section{In Reply:}

Our correspondents' comments relate to individual therapeutic variants. It is worth re-stating that diabetology has a substantial problem with evidence, or rather, 
the lack thereof, because the effectiveness of blood glucose lowering vis-à-vis mortality and complications has been confirmed to a very limited extent in appropriate randomized prospective studies (1). The threshold above which raised blood glucose concentrations will trigger the complications that are typical for diabetes is unclear, and this is also the case for the question regarding which individual factors may pose a particular risk. By contrast, high-level evidence supports the fact that therapy induced hypoglycemia constitutes a relevant risk factor (1). This is reflected in the "relaxed" recommendations of the current guidelines, as we showed in our article. Metformin is recommended by all guidelines, although the evidence-from a small group treated with metformin in the UKPDS Study (3) - is weak (2). It was also in the UKPDS Study that mortality was significantly raised for the combination of sulfonylureas with metformin (3); the national disease management guideline explicitly makes reference to this finding.

With regard to sulfonylureas, our colleagues from DEGAM/AkdÄ focus only on the evidence that supports their argument. The risk of hypoglycemia and weight gain affects patients to very different degrees under treatment with sulfonylureas. The DPP-4 and SGLT-2 inhibitors are clearly superior in this respect, which is relevant for some patients and therefore has to be explained in a CME article.

In the Look AHEAD Study, lifestyle did not affect cardiovascular end points, as Meyer reminds us. But the control group had displayed extremely healthy behaviors and lost $4.5 \mathrm{~kg}$, compared with $6 \mathrm{~kg}$ in the intervention group - possibly thanks to the comprehensive press coverage - so that the weight difference was only $1.5 \mathrm{~kg}$. Physical activity was evidently increased only slightly-something that needs to be considered in clinical practice. However, one would hardly advise against healthy behavior-even if this might seem justified on the basis of evidence criteria alone. By contrast, dietary factors - the Mediterranean diet, to be more specific-were successful in significantly lowering cardiovascular mortality; this also applied to the 3700 diabetes patients in this randomized controlled study (4). According to subgroup analyses of the ADVANCE and ONTARGET studies $(5,6)$, moderate consumption of alcohol, defined as up to $36 \mathrm{~g} /$ day, in diabetes patients resulted in a significant reduction in mortality and microvascular/macrovascular complications; however, neuropathy was insufficiently evaluated. With our colleague Roth, we are looking forward to study results that are imminently expected from Israel.

DOI: 10.3238/arztebl.2014.0433b

\section{REFERENCES}

1. Boussageon R, Bejan-Angoulvant T, Saadatian-Elahi M, et al.: Effect of intensive glucose lowering treatment on all cause mortality, cardiovascular death, and microvascular events in type 2 diabetes: meta-analysis of randomised controlled trials. BMJ 2011; 343: d4169.

2. Boussageon R, Supper I, Bejan-Angoulvant T, et al.: Reappraisal of metformin efficacy in the treatment of type 2 diabetes: a metaanalysis of randomised controlled trials. PLoS Med 2012; 9: e1001204

3. UK Prospective Diabetes Study (UKPDS) Group: Effect of intensive blood-glucose control with metformin on complications in overweight patients with type 2 diabetes (UKPDS 34). Lancet 1998; 352: 854-65.

4. Estruch R, Ros E, Salas-Salvado J, et al.: Primary prevention of cardiovascular disease with a Mediterranean diet. N Engl J Med 2013; 368: 1279-90.

5. Blomster Jl, Zoungas S, Chalmers J, et al.: The relationship between alcohol consumption and vascular complications and mortality in individuals with type 2 diabetes mellitus. Diabetes Care 2014.

6. Dunkler D, Dehghan M, Teo KK, et al.: Diet and kidney disease in high-risk individuals with type 2 diabetes mellitus. JAMA Intern Med 2013; 173: 1682-92.

7. Pfeiffer AFH, Klein $\mathrm{HH}$ :The treatment of type 2 diabetes. Dtsch Arztebl Int 2014; 111: 69-82.

Prof. Dr. med. Andreas F. H. Pfeiffer

Berlin und Potsdam

andreas.pfeiffer@charite.de

Prof. Dr. med. Harald Klein

Bochum

\section{Conflict of interest statement}

Prof. Pfeiffer has received consulting fees from Novo, Berlin Chemie, Novartis, Astra Zeneca/BMS, Sanofi, Lilly, and Boehringer-Ingelheim and reimbursement of conference participation fees from A \& A and Boehringer Ingelheim. He has received payment for preparing continuing medical education presentations from Lilly, Thieme, PriMed, Novo, Berlin Chemie, MSD, and Sanofi. He has received payment to a third-party-funding account for performing clinical trials on behalf of Roche, Takeda, Astra Zeneca, and Novo. He has received financial support from Novartis, Bayer, and Rettenmayer \& Söhne for a research project that he initiated.

Prof. Klein has received consulting fees from GlaxoSmithKline, Sanofi-Aventis, Janssen-Cilag, and AstraZeneca and reimbursement of conference participation fees from Lilly, Novartis, and AstraZeneca. He has received payment for preparing continuing medical education presentations from Novo Nordisk. He has received financial support from GlaxoSmithKline and Sanofi Aventis for a research project that he initiated. 